\title{
Relationship between T-cell receptor beta chain sequences and human cytomegalovirus infection in allogeneic hematopoietic stem cell transplant recipients
}

\author{
ZHIHUA WU ${ }^{1,2}$, HUIPING ZHANG ${ }^{3}$, MIN JIN ${ }^{1}$, HANYING LIANG $^{1}$, YAPING HUANG ${ }^{1}$, RONG YANG $^{1}$, \\ GENYONG GUI $^{1}$, HUIQI WANG ${ }^{1}$, SHENGNAN GONG ${ }^{1}$, JINDONG WANG ${ }^{1}$ and JUN FAN ${ }^{1}$
}

\begin{abstract}
${ }^{1}$ Virology Department, State Key Laboratory for Diagnosis and Treatment of Infectious Diseases, Collaborative Innovation Center for Diagnosis and Treatment of Infectious Diseases, The First Affiliated Hospital, College of Medicine, Zhejiang University,

Hangzhou, Zhejiang 310003; ${ }^{2}$ Department of Clinical Laboratory, Tongde Hospital of Zhejiang Province, Hangzhou, Zhejiang 310012; ${ }^{3}$ Department of Clinical Laboratory, Hangzhou Cancer Hospital, Hangzhou, Zhejiang 310002, P.R. China
\end{abstract}

Received January 20, 2016; Accepted February 10, 2017

DOI: $10.3892 / \mathrm{mmr} .2017 .6453$

\begin{abstract}
In the present study, clonal amplifications of T-cell receptor $\beta$ variable (TCR BV) linked to human cytomegalovirus (HCMV) infection were detected in recipients of allogeneic hematopoietic stem cell transplants (HSCT), and certain relationships between them were identified. Furthermore, the relationship between TCR BV sequences and HCMV infections was investigated. The results indicated that the 3 recipients of HSCT had monoclonal expansion of specific TCR BV clones following HSCT. Among these recipients, 2 suffered from pp65 and immediate early (IE) antigenemia. These patients demonstrated preferential expansion of TCR BV9 (QVRGGTDTQ) and TCR BV11 (VATDFQ). The remaining recipient did not express TCR BV9 and TCR BV11, nor did this individual have pp65 and IE antigenemia. These results suggest that expression of TCR BV9 and TCR BV11 may be associated with HCMV antigenemia, and may be involved in the immune response. The amino acid
\end{abstract}

Correspondence to: Professor Jun Fan, Virology Department, State Key Laboratory for Diagnosis and Treatment of Infectious Diseases, Collaborative Innovation Center for Diagnosis and Treatment of Infectious Diseases, The First Affiliated Hospital, College of Medicine, Zhejiang University, 79 Qingchun Road, Hangzhou, Zhejiang 310003, P.R. China

E-mail: fanjun@zju.edu.cn

Abbreviations: TCR BV, T-cell receptor $\beta$ variable; CDR3, complementarity determining region 3; HSCT, allogeneic hematopoietic stem cell transplantation; HCMV, human cytomegalovirus; GMSP, gene melting spectral pattern; PBMCs, peripheral blood mononuclear cells; ELISA, enzyme-linked immunosorbent assay; CTLs, cytotoxic T lymphocytes; HBV, hepatitis B virus; HIV, human immunodeficiency virus

Key words: T-cell receptor, human cytomegalovirus, allogeneic hematopoietic stem cell transplantation, recipients, antigenemia, spectrum sequences 'QVRGGTDTQ' and 'VATDFQ' may be involved in HCMV reactivation in patients who have undergone HSCT. Assessment of the TCR BV families may provide valuable insight into HCMV pathogenesis and may aid in the diagnosis and therapy for HSCT recipients infected with HCMV.

\section{Introduction}

Human cytomegalovirus (HCMV) infection is a major cause of high morbidity and mortality in patients that have undergone allogeneic hematopoietic stem cell transplantation (HSCT) $(1,2)$. Cellular immunity through antigen-specific cytotoxic T lymphocytes (CTLs) is involved in long-term suppression $(3,4)$. Each individual CTL has a specific complementarity determining region 3 (CDR3) located in the $\mathrm{T}$ cell receptor $\beta$ variable (TCR BV) region, which occurs as a result of $\mathrm{V}(\mathrm{D}) \mathrm{J}$ recombination and junctional diversity. During an antiviral immune response, the interactions between a TCR and its antigen-specific peptides, which are mediated in part by CDR3, result in a polyclonal expansion of $\mathrm{T}$ cells and clones expressing different CDR3 sequences (5). Determining the frequency of specific CDR3 sequences within a T-cell population may provide an accurate estimation of the extent of clonal expansion and the function of the expanded populations. It is well-known that TCRs are closely associated with viral infections, specifically hepatitis B virus (HBV) and human immunodeficiency virus (HIV) $(6,7)$. The occurrence of HCMV reactivation in patients following HSCT is also well documented $(8,9)$. However, the underlying mechanisms responsible for this reactivation remain unknown. In the present study, reverse transcription-quantitative polymerase chain reaction (RT-qPCR) and DNA melting curve analysis were used to evaluate the distribution of TCR BV CDR3 genes expressed in peripheral blood mononuclear cells (PBMCs) isolated from patients that had undergone HSCT. This analysis evaluated the impact of T-cells on HCMV reactivation beyond $\mathrm{T}$ cell clonal expansion, thus providing molecular evidence that an association exists between HCMV infection and immune dysregulation in patients following HSCT. 


\section{Materials and methods}

Subjects. A total of 3 HSCT recipients at The First Affiliated Hospital, Zhejiang University School of Medicine (Hangzhou, China) were enrolled in the present study between January 2011 and December 2012. One healthy donor from the same hospital was enrolled as a control, in December 2012. Patients with the following viral infections were excluded from this study: HIV, HBV, hepatitis A virus, hepatitis C virus, hepatitis D virus, hepatitis $\mathrm{E}$ virus, herpes simplex virus, and Epstein-Barr virus. Recipient 1 was not infected with HCMV, while repeated HCMV reactivation occurred in recipients 2 and 3. Additional patient information is listed in Table I. The present study was approved by the Ethics Committee of the First Affiliated Hospital at the Medical School of Zhejiang University (Hangzhou, China). Written, informed consent was obtained from patients according to the Declaration of Helsinki.

TCR BV CDR3 genes expressed in PBMCs from all subjects were detected using RT-qPCR and a DNA melting curve analysis at the third month after transplantation $(10,11)$. HCMV-pp65, HCMV-immediate early protein (HCMV-IE), HCMV-immunoglobulin (HCMV-Ig) $\mathrm{M}$ and HCMV-IgG were detected on the same day, and serial analysis of HCMV infection continued monthly until $\sim 1$ year after HSCT.

RNA extraction and cDNA synthesis. A total of $5 \mathrm{ml}$ blood was collected from each subject, and PBMCs were isolated using a Ficoll-Paque density gradient technique. Total RNA was extracted using TRNzol reagent (Tiangen Biotech Co., Ltd., Beijing, China), according to the manufacturer's protocol. Total RNA was reverse transcribed to cDNA using a RevertAid First Strand cDNA Synthesis kit (Thermo Fisher Scientific, Inc., Waltham, MA, USA) according to the manufacturer's protocol. Sample RNA of 1-5 $\mu \mathrm{g}$ was reverse transcribed with the OligodT18 primer in a $20 \mu 1$ reaction volume and stored at $-80^{\circ} \mathrm{C}$ prior to being used as the template for PCR amplification.

$R T$-qPCR amplification of CDR3 $c D N A$. In this study, we used primers for $24 \mathrm{TCR}$ BV gene families (Table II) (12). A TransStart TM Green qPCR Super Mix (Tiangen Biotech Co., Ltd., Beijing, China) was used for qPCR. PCR reactions contained $0.5 \mu \mathrm{l}$ reverse primer (TCR BV), $0.5 \mu 1$ forward primer (24 TCR BV genes), $1 \mu 1$ template cDNA, $12.5 \mu 1$ qPCR Super Mix (2X), $0.5 \mu 1$ passive reference (50X), and $10 \mu \mathrm{l}$ RNase-free distilled water, to a final volume of $25 \mu \mathrm{l}$. Reactions were performed using an ABI 7500 system and were analyzed with v2.0.6 software (Applied Biosystems; Thermo Fisher Scientific, Inc.). The reaction parameters were as follows: $2 \mathrm{~min}$ at $94^{\circ} \mathrm{C}$ to activate the GoTaq DNA polymerase enzyme (Promega Corporation, Madison, WI, USA), followed by 45 cycles at $94^{\circ} \mathrm{C}$ for $15 \mathrm{sec}, 56.0^{\circ} \mathrm{C}$ for $25 \mathrm{sec}, 72^{\circ} \mathrm{C}$ for $35 \mathrm{sec}, 80^{\circ} \mathrm{C}$ for $2 \mathrm{sec}$, and a final extension at $72^{\circ} \mathrm{C}$ for $8 \mathrm{~min}$. The melting step was performed by slow heating from 75 to $95^{\circ} \mathrm{C}$ with a ramping rate of $0.2^{\circ} \mathrm{C} / \mathrm{s}$, during which the fluorescence signal was continuously measured. Simultaneous amplification of TCR $\beta$ chain constant 1 and glyceraldehyde 3-phosphate dehydrogenase were used as positive controls.
$C D R 3$ sequencing of monoclonal TCR BV families. Using this melting curve, PCR products from the TCR BV gene families that had a single-peak expansion were selected. Single-peak expansion was defined as 'monoclonal', and appeared as only one main peak in the gene melting spectral pattern (GMSP). 'Nonskewed' means polyclonal amplification, which appeared as no visibly apparent main peak. The PCR products were re-amplified using GoTaq DNA polymerase (Promega Corporation, Madison, WI, USA) by touchdown PCR. The parameters were as follows: pre-incubation at $95^{\circ} \mathrm{C}$ for $2 \mathrm{~min}$, $95^{\circ} \mathrm{C}$ for $30 \mathrm{sec}, 58.5^{\circ} \mathrm{C}$ for $40 \mathrm{sec}$ and $72^{\circ} \mathrm{C}$ for $45 \mathrm{sec}$, and 6 cycles with annealing temperature decreasing $0.5^{\circ} \mathrm{C}$ per cycle, followed by 34 cycles of $95^{\circ} \mathrm{C}$ for $45 \mathrm{sec}, 56^{\circ} \mathrm{C}$ for $45 \mathrm{sec}$ and $72^{\circ} \mathrm{C}$ for $45 \mathrm{sec}$. At the end, a terminal elongation step at $72^{\circ} \mathrm{C}$ for 8 min was added. Nested PCR products were sequenced using an ABI 3730 DNA Sequencer (Applied Biosystems; Thermo Fisher Scientific, Inc.). Samples were sent to Sangon Biotech Co., Ltd., Shanghai, China, and sequenced there. Results were analyzed automatically by a $3730 x 1$ DNA Analyzer and the sequencing reagent was BigDye terminator version 3.1.

Analysis of CDR 3 sequences. Chromas software version 2.22 (Technelysium Pty Ltd., Brisbane, Australia) was used to translate nucleotide sequences into amino acid sequences (13). When the PCR nucleic acid product underwent electrophoresis and only one band was present, this represented direct sequencing. The presence of a thin strip in addition to a clear band, suggested cloned sequencing. Samples were sent to Sangon Biotech Co., Ltd., and sequenced there.

Detection of HCMV-pp65 and IE antigenemia. Peripheral blood samples were collected in ethylenediaminetetraacetic acid (EDTA)-anticoagulant tubes. To evaluate pp65 and IE antigenemia a standard two-step immunohistochemical method was used, as described previously $(14,15)$. Briefly, $5 \times 10^{4}$ PBMCs were fixed on polylysine-coated slides, and incubated with mouse anti-HCMV (pp65 catalog no. ab53495; IE catalog no. ab53489; 1:100; Abcam, Cambridge, UK) monoclonal antibodies at $37^{\circ} \mathrm{C}$ for $30 \mathrm{~min}$, and horseradish peroxidase-conjugated rabbit anti-mouse IgG polyclonal antibody (catalog no. ab6728; 1:250; Abcam) at $37^{\circ} \mathrm{C}$ for $30 \mathrm{~min}$. A total of $5 \times 10^{4}$ PBMCs were fixed on one slide, and every sample was fixed on 2 slides. Results were quantified based on the average number of brown stained positive cells per $5 \times 10^{4}$ leukocytes in the 2 slides. Cells were observed under a light microscope (BH-2; Olympus Corporation, Tokyo, Japan) with magnification $\times 100 / 200 / 400$.

Detection of HCMV-IgG/IgM. Blood samples were collected in EDTA-anticoagulant tubes. HCMV-antibody serostatus ( $\operatorname{IgG}$ and $\operatorname{IgM}$ ) was determined using enzyme-linked immunosorbent assays (ELISA) according to the manufacturer's protocols (Dia.Pro Diagnostic Bioprobes s.r.l., Milan, Italy).

Statistical analysis. Differences in HCMV antigenemia and the presence of HCMV-IgG/IgM among the 3 HSCT recipients were examined using one-way analysis of variance followed by Tukey's test. Graphical analyses of results were generated using Prism 5 (Graph-Pad, San Diego, CA, USA). P $<0.05$ was considered to indicate a statistically significant difference. 
Table I. Characteristics of recipients and the healthy control.

\begin{tabular}{|c|c|c|c|c|}
\hline General information & Recipient1 & Recipient 2 & Recipient 3 & Healthy control \\
\hline Sex & Female & Female & Male & Male \\
\hline Age & 31 & 24 & 20 & 25 \\
\hline Underlying disease & CML & AMMOL(M4) & ALL & None \\
\hline HIV & - & - & - & - \\
\hline HSV & - & - & - & - \\
\hline HAV & - & - & - & - \\
\hline $\mathrm{HBV}$ & - & - & - & - \\
\hline $\mathrm{HCV}$ & - & - & - & - \\
\hline HDV & - & - & - & - \\
\hline $\mathrm{HEV}$ & - & - & - & - \\
\hline EBV & - & - & - & - \\
\hline HCMV-IgG & + & + & + & + \\
\hline Conditioning regimen & $\begin{array}{l}\text { ARA-C+BUCY+ } \\
\text { Me-CCNU+ATG }\end{array}$ & $\begin{array}{l}\text { ARA-C+BUCY+ } \\
\text { ATG+MeCCNU }\end{array}$ & BUCY+MeCCNU & N/A \\
\hline Blood type & $\mathrm{B} / \mathrm{B}$ & $\mathrm{B} / \mathrm{B}$ & $\mathrm{B} / \mathrm{B}$ & $\mathrm{B}$ \\
\hline HLA & HLA0201 & HLA0201 & HLA0201 & HLA0201 \\
\hline Immunosuppressant regimen & CSA, MMF, PRED & CSA, MMF, PRED & CSA, MMF, PRED & $\mathrm{N} / \mathrm{A}$ \\
\hline Antiviral pretreatment & $\mathrm{GCV}, \mathrm{ACV}$ & $\mathrm{GCV}, \mathrm{ACV}$ & $\mathrm{GCV}, \mathrm{ACV}$ & N/A \\
\hline
\end{tabular}

CML, chronic myelogenous leukemia; ALL, acute lymphocytic leukemia; AMMOL, acute myelomonocytic leukemia; HLA, human leukocyte antigen; GCV, ganciclovir; ACV, acyclovir; CSA, cyclosporin A; MMF, mycophenolate mofetil; PRED, prednisone; ARA-C, cytosine arabinoside; BU, busulfan; CY, cyclophosphamide; MeCCNU, methyl-cyclohexyl-nitrosamine; ATG, anti-thymocyte globulin; N/A, not applicable .

\section{Results}

Frequency of skewed TCR BV gene families and CDR3 sequences derived from monoclonal TCR BV expansion in 3 recipients of HSCT. All 3 recipients of HSCT demonstrated preferential expansion of specific TCR BV gene families. The characteristics of TCRBV CDR 3 expression are visualized in Fig. 1. For recipient 1, 5 monoclonal peaks were observed and TCR BV5.1 was preferentially expressed. In recipient 2, 4 monoclonal peaks were observed, including TCR BV9, TCR BV11, and TCR BV17. In recipient 3, 10 monoclonal peaks were observed and TCR BV9, TCR BV11, and TCR BV21 were selectively expressed. Recipients 2 and 3 had 2 gene families in common; TCR BV9 and TCR BV11 (Fig. 1).

A single peak in a GMSP indicates monoclonal expansion of a particular TCR BV clone, and this was verified by direct sequencing. Representative amino acid sequences of the TCR BV CDR3 in PBMCs from all recipients are listed in Table III. All recipients had a CDR3 sequence length of 5-12 amino acids. The amino acid sequences of TCR BV9 (QVRGGTDTQ) and TCR BV11 (VATDFQ) were similar between recipients 2 and 3 . The healthy control expressed a non-skewed TCR BV repertoire. Representative GMSPs for non-skewed and oligoclonally expanded TCRBV gene families are visualized in Fig. 2.

Detection of pp65 and IE antigenemia. In all transplant recipients, pp65 and IE antigenemia were monitored $\sim 10$ times for up to one year following HSCT. Samples obtained from recipient 1 were typically pp65- and IE-negative, while recipients 2 and 3 consistently tested positive for pp65 (Fig. 3A) and IE antigenemia (Fig. 3B). For recipient 2, the mean number of pp65-positive cells was $4.5 / 5 \times 10^{4} \mathrm{PBMCs}$ (range, 1-10 positive cells $/ 5 \times 10^{4} \mathrm{PBMCs}$ ), and the mean number of IE-positive cells was $4.3 / 5 \times 10^{4} \mathrm{PBMCs}$ (range, $1-9$ positive cells $/ 5 \times 10^{4}$ PBMCs). For recipient 3 , a mean number of pp65-positive cells of $4.6 / 5 \times 10^{4} \mathrm{PBMCs}$ (range, $2-8$ positive cells $/ 5 \times 10^{4} \mathrm{PBMCs}$ ) and a mean number of IE-positive cells of $4.2 / 5 \times 10^{4} \mathrm{PBMCs}$ (range, $2-8$ positive cells $/ 5 \times 10^{4} \mathrm{PBMCs}$ ) was observed.

Detection of HCMV serostatus (IgG and IgM). Over the course of 1 year following HSCT, HCMV-specific IgG and $\operatorname{IgM}$ were investigated on 10 separate occasions for all 3 recipients, during detection of pp65 and IE antigens. During the present study, all recipients remained HCMV-IgG-positive and HCMV-IgM-negative.

Analysis of HCMV-pp65 and -IE antigenemia levels. The levels of HCMV-pp65 and IE antigenemia were evaluated using a standard two-step immunohistochemical method on 60 samples from 3 recipients following HSCT. All recipients were tested on 10 separate occasions, up to one year following HSCT and all data of HCMV-pp65 or HCMV-IE collected during this period were involved. Statistically significant differences were observed in the levels of HCMV-pp65 ( $\mathrm{P}<0.05$; Fig. 3A) and -IE $(\mathrm{P}<0.05$; Fig. 3B) antigenemia between recipients 1 and 2. This result was also observed between recipients 1 and 3 $(\mathrm{P}<0.05$ and $\mathrm{P}<0.05$, respectively; Fig. $3 \mathrm{~A}$ and $\mathrm{B}$, respectively). 
Table II. Primers of 24 TCR BV families and GAPDH.

\begin{tabular}{|c|c|c|}
\hline $\begin{array}{l}\text { Name of } \\
\text { primer }\end{array}$ & Sequence $\left(5^{\prime}-3^{\prime}\right)$ & $\begin{array}{l}\mathrm{V} \text { region } \\
\text { to } \mathrm{CDR} 3\end{array}$ \\
\hline BV1 & gcacaacagttccctgacttgcac & $90 \mathrm{bp}$ \\
\hline BV2 & tcatcaaccatgcaagcctgacct & $90 \mathrm{bp}$ \\
\hline BV3 & gtctctagagagaagaaggagcgc & $91 \mathrm{bp}$ \\
\hline BV4 & acatatgagagtggatttgtcatt & 124 bp \\
\hline BV5.1 & atacttcagtgagacacagagaaac & 142 bp \\
\hline BV5.2 & ttccctaactatagctctgagctg & $81 \mathrm{bp}$ \\
\hline BV6 & aggcctgagggatccgtctc & $85 \mathrm{bp}$ \\
\hline BV7 & cctgaatgccccaacagctctc & $91 \mathrm{bp}$ \\
\hline BV8 & atttactttaacaacaacgttccg & 128 bp \\
\hline BV9 & cctaaatctccagacaaagctcac & $91 \mathrm{bp}$ \\
\hline BV10 & ctccaaaaactcatcctgtacctt & $83 \mathrm{bp}$ \\
\hline BV11 & tcaacagtctccagaataaggacg & $97 \mathrm{bp}$ \\
\hline BV12 & aaaggagaagtctcagat & 118 bp \\
\hline BV13.1 & caaggagaagtccccaat & 118 bp \\
\hline BV13.2 & ggtgagggtacaactgcc & 136 bp \\
\hline BV14 & gtctctcgaaaagagaagaggaat & $91 \mathrm{bp}$ \\
\hline BV15 & agtgtctctcgacaggcacaggct & $95 \mathrm{bp}$ \\
\hline BV16 & aaagagtctaaacaggatgagtcc & 139 bp \\
\hline BV17 & cagatagtaaatgactttcag & 139 bp \\
\hline BV18 & gatgagtcaggaatgccaaaggaa & 124 bp \\
\hline BV19 & caatgccccaagaacgcaccetgc & 88 bp \\
\hline BV20 & agctctgaggtgccccagaatctc & $-131 b p^{a}$ \\
\hline BV21 & gattcacagttgcctaagga & $121 \mathrm{bp}$ \\
\hline BV22 & cagagaagtctgaaatattcga & 128 bp \\
\hline BV23 & gatcgattctcagctcaacag & 103 bp \\
\hline BV24 & aaagattttaacaatgaagcagac & 133 bp \\
\hline TCR BC1 & ttctgatggctcaaacac & \\
\hline
\end{tabular}

anti-sense

GAPDH

anti-sense

GAPDH sense cgaccactttgtcaagctca
Comparison of HCMV antigenemia levels between TCR $B V 9 / T C R$ BV11-positive recipients and the TCR BV9/TCR $B V 11-n e g a t i v e$ recipient. Recipients who preferentially expressed TCR BV9 and TCR BV11 were defined as TCR $\mathrm{BV}^{+}$and TCR BV11 ${ }^{+}$, respectively. Among the 3 recipients

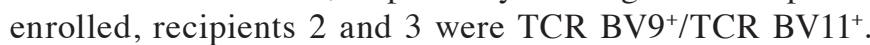
'QVRGGTDTQ' was the conserved amino acid sequence in TCR BV9 CDR3 and 'VATDFQ' was observed in TCR BV11 CDR3 (Table III). Two recipients exhibited pp65 and IE antigenemia, while being simultaneously positive for HCMV-IgG and negative for HCMV-IgM. Recipient 1 was TCR BV9-/TCR BV11', HCMV-IgG ${ }^{+}$and HCMV-IgM-', but free of pp65 and IE antigenemia (Table IV). To determine whether HCMV reactivation was associated with a specific amino acid sequence of TCR BV CDR3, HCMV antigenemia status were compared between the TCR BV9+/TCR $\mathrm{BV}_{11}{ }^{+}$recipients and the TCR BV9-/TCR BV11' recipient (Table IV). This revealed that HCMV reactivation may be associated with TCR BV9 and TCR BV11, and a specific amino acid sequence of TCR BV CDR3 may be involved in HCMV infection.

\section{Discussion}

Although HCMV reactivation is commonly observed following immune dysfunction from HSCT, the molecular mechanisms that drive this phenomenon remain unknown. T cell immune responses induced by viral antigens are involved in the inflammatory process of stemming viral infections. CTLs are involved in HCMV control and pathogenesis (16). In PBMCs, $>95 \%$ of the T cells are $\alpha \beta+(17)$. During T cell development, the TCR $\beta$ chain undergoes rearrangement earlier than the $\alpha$ chain, according to rules of allelic exclusion. Therefore, analysis of the TCRBV CDR3 gene may be beneficial in determining the clonality of a particular $\mathrm{T}$ cell response, and therefore be used as a marker for the functional status of T cells (18). Studies focused on TCR BV gene families may provide novel insights and a solid foundation for the prevention, diagnosis, and treatment of viral infections (19).

The TCR BV gene family demonstrated a diverse, non-skewed expansion in PBMCs derived from the healthy control. However, particular TCR BV families were preferentially expressed or biased, and emerged as a group of monoclonal (oligoclonal) T cells in the PBMCs of all 3 recipients of HSCT. Due to the long-term use of systemic steroids, the $\mathrm{T}$ cell response to HCMV is impaired and HCMV reactivation often occurs in patients that have undergone $\operatorname{HSCT}(20,21)$. This was determined by the restricted use and oligoclonal expression of TCR BV families following transplantation. The TCR BV gene rearrangement was random without antigen stimulation (22). TCR gene transfer was developed as a promising means of generating large numbers of $T$ cells of a given antigen specificity and functional avidity ex vivo. This technique has demonstrated significant potential for clinical use (23-26).

In the present study, TCR $\beta$ chain sequences and the presence of HCMV infection were analyzed in recipients of HSCT. A relationship between HCMV reactivation and TCR BV families was observed. TCR BV9 and TCR BV11-positive recipients had HCMV antigenemia. 'QVRGGTDTQ' was the

most common amino acid sequence observed for TCR BV9 significant difference between HCMV-IgG and IgM optical density/cut-off among the 3 recipients was observed. $(\mathrm{P}>0.05)$.
However, there was no significant difference in the levels of pp65 and IE antigenemia between recipients 2 and 3 ( $P>0.05$ Comparison of the HCMV serostatus (IgG and $\operatorname{Ig} M$ ) among recipients of $H S C T$. $\mathrm{HCMV}$-specific-IgG and $\mathrm{IgM}$ was detected using ELISA on 60 samples from 3 patients 1 year following HSCT. Each recipient was tested 10 times on separate occasions. During the study, all recipients remained $\mathrm{HCMV}$-specific-IgG-positive and IgM-negative. No 
Table III. Representative amino acid sequences of monoclonal TCRBV populations from 3 recipients of allogeneic hematopoietic stem cell transplantation.

\begin{tabular}{|c|c|c|c|c|}
\hline Recipient & Primer BV & $\mathrm{V} \beta$ & CDR3 & Jbeta \\
\hline 1 & BV5.1 & SALYLCASS & SPRDRGYGDTQ & YFGPGTRLTVLED \\
\hline \multirow[t]{3}{*}{2} & BV9 & SAVYFCASS & QVRGGTDTQ & YFGPGTRLTVLET \\
\hline & BV11 & TSQHFCASS & VATDEQ & FFGPGTRLTVLED \\
\hline & BV17 & TAFYLCASS & IGQGNTEA & FFGQGTRLTV \\
\hline \multirow[t]{3}{*}{3} & BV9 & SAVYFCASS & QVRGGTDTQ & YFGPGTRLTVLED \\
\hline & BV11 & TSQYLCASS & VATDEQ & FFGPGTWLTVLED \\
\hline & BV21 & SAVYLCASS & GMIGRLTDTQ & YFGPGTRLTVLED \\
\hline
\end{tabular}

Polymerase chain reaction products were extracted when their gene melting spectral patterns revealed a single peak, and directly sequenced or sequenced following cloning. Amino acid sequences of TCR BV9 (QVRGGTDTQ) and TCR BV11 (VATDFQ) were similar between recipients 2 and 3. TCR BV, T-cell receptor $\beta$ variable; CDR3, complementarity determining region 3 .

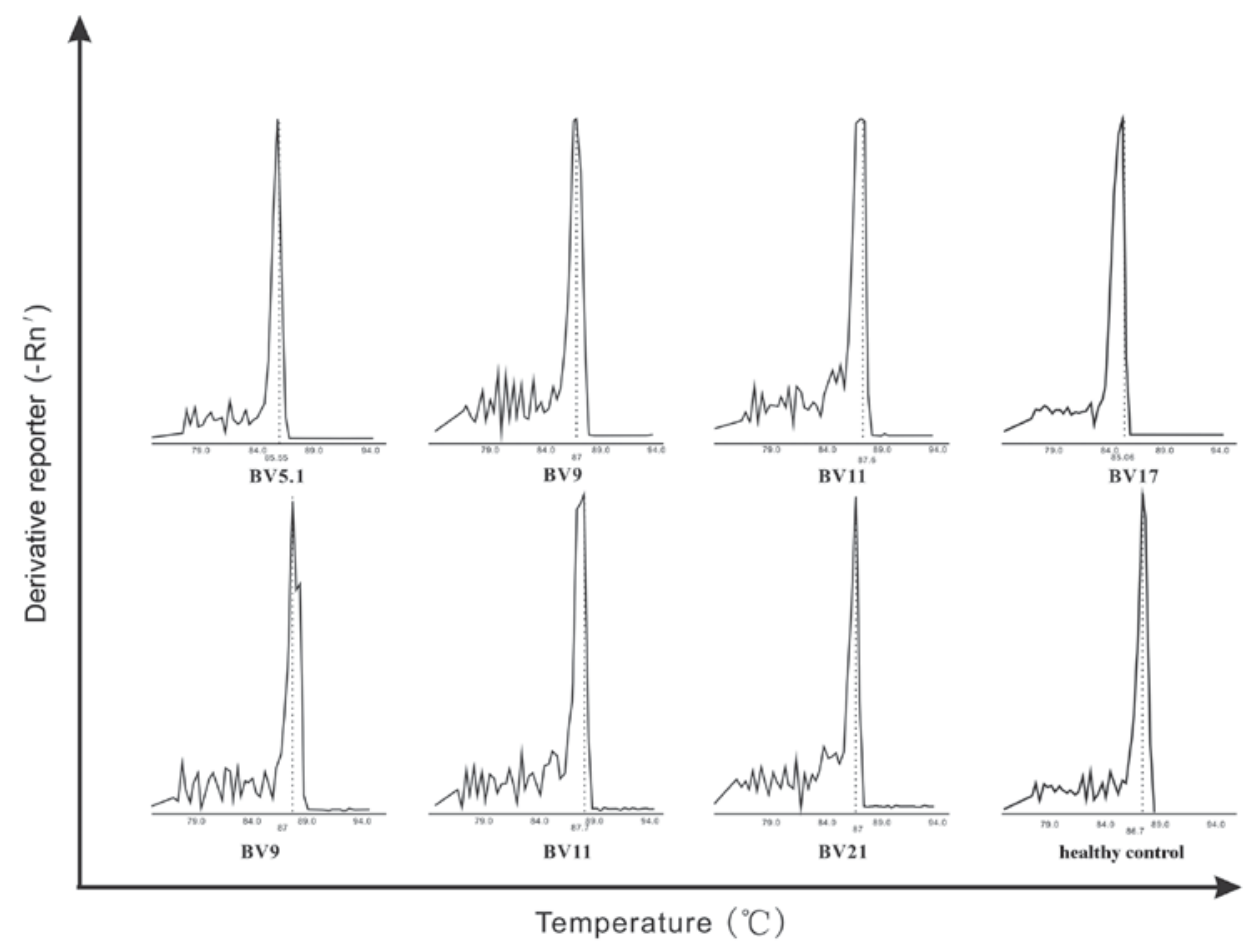

Figure 1. Representative gene melting spectral pattern with single-peak (monoclonal expansion) for TCR BV in peripheral blood mononuclear cells from all 3 transplant recipients. The TCR BV gene families in the top graphs correspond to recipients 1 (TCR BV5.1) and 2 (TCR BV9, 11 and 17). TCR BV gene families in the bottom graphs correspond to recipient 3 (TCR BV9, TCR BV11, and TCR BV21) and the healthy control. The x-axis of each plot corresponds to the melting temperature. A decrease in fluorescence vs. temperature (derivative reporter, -RN') is plotted on the y-axis. TCR BV, T-cell receptor $\beta$ variable.

CDR3, and 'VATDFQ' was observed for TCR BV11 CDR3. The explanation for this finding may be the multifarious usage of distinctive TCR BV families. Conserved sequences of the TCR BV repertoire were diverse without peptide stimulation, but became more restrictive following stimulation by the HCMV peptide. The clinical course of HCMV reactivation was affected by the usage of TCR BV9 and TCR BV11 in recipients of HSCT. Expression of TCR BV9 and TCR BV11 may be associated with HCMV antigenemia, and may be involved in the immune response. The amino acid sequences 'QVRGGTDTQ' and 'VATDFQ' may be beneficial for eliciting an anti-viral response, as well as contributing to HCMV clearance. TCR BV with the sequences 'QVRGGTDTQ' and 'VATDFQ' may, therefore, be a risk factor for HCMV reactivation.

Although the number of patients that underwent HSCT enrolled in the present study was relatively small, each of the patients underwent detailed longitudinal analysis with 10 separate follow-ups over the course of 1 year. In total, $>120$ samples were analyzed. In addition, the contents of the present study are only a part of longer-term research work. Another challenge regarding the methodology is that the controls would have been improved had they been HCMV-negative patients that underwent HSCT. However, $100 \%$ Han Chinese people 


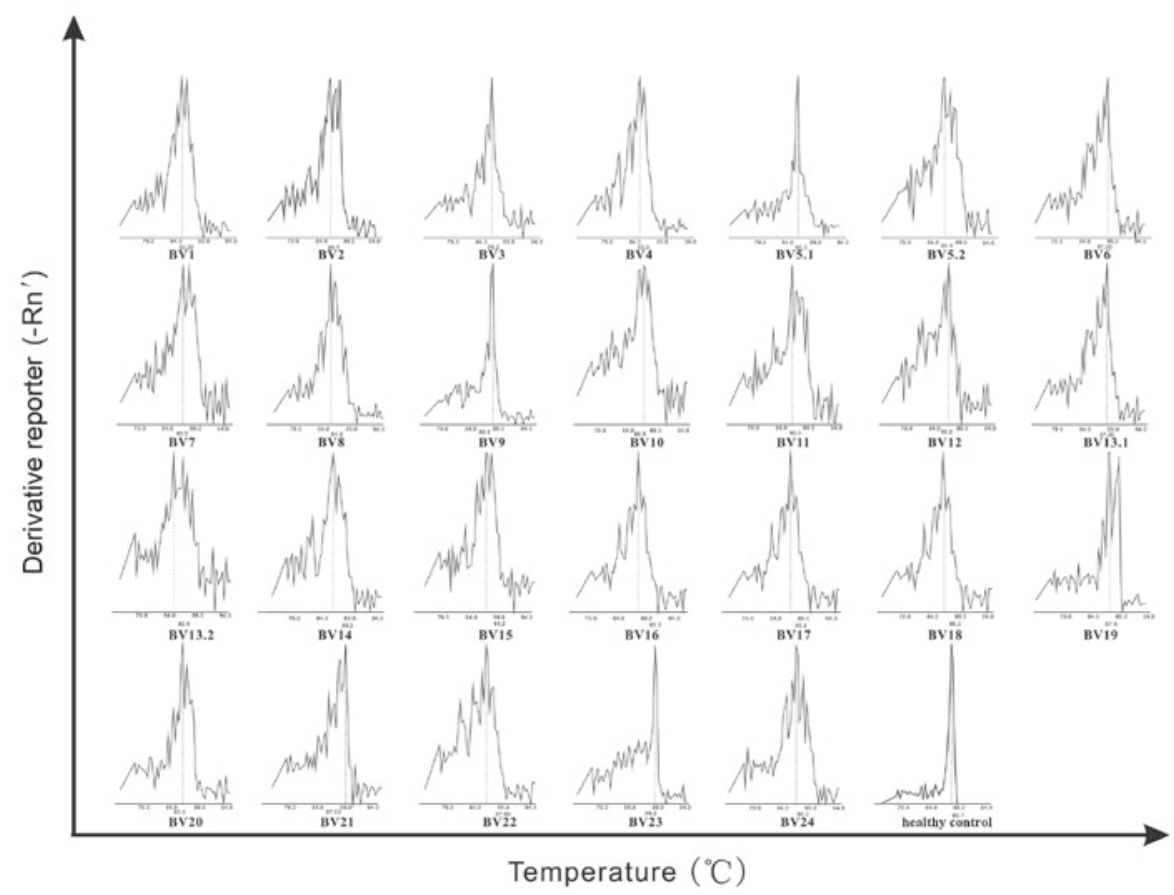

Figure 2. Representative gene melting spectral patterns of non-skewed TCR BV distributions in peripheral blood mononuclear cells from the healthy control. In total, 24 TCR BV gene families were assessed, including TCR BV5 and TCR BV13. The x-axis of each plot corresponds to the melting temperature, the decrease in fluorescence vs. temperature (derivative reporter - $R N^{\prime}$.) is plotted on the y-axis. TCR BV, T-cell receptor $\beta$ variable.
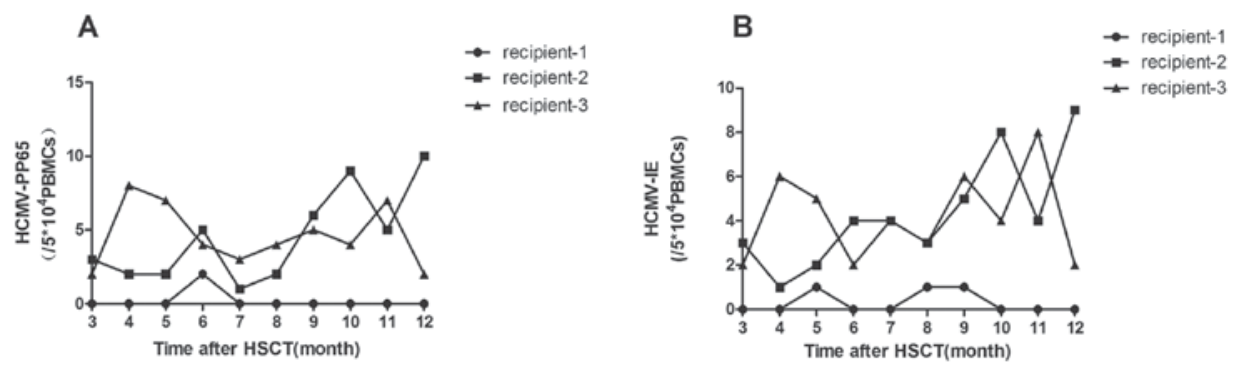

C

D
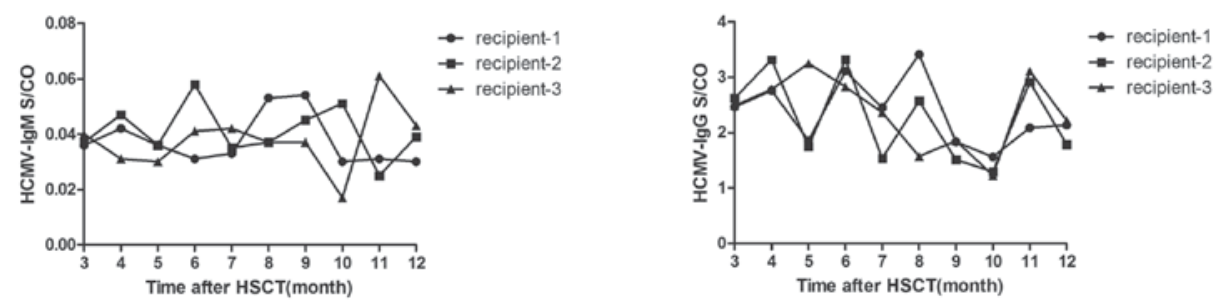

Figure 3. Comparison of HCMV antigenemia levels and serostatus. Levels of (A) pp65 antigenemia, (B) IE antigenemia, (C) HCMV-IgM S/CO and (D) HCMV-IgG S/CO. S/CO, optical density of the sample/cut-off; HCMV, human cytomegalovirus; IE, immediate early; HSCT, allogeneic hematopoietic stem cell transplantation.

are HCMV-IgG positive (27), and HCMV-IgG negative HSCT recipients were not identified. Therefore, such negative controls were not used in the present study.

Given that immune reconstitution must start from the beginning for a patient who has undergone HSCT, these patients are at high risk for HCMV reactivation. The results from the present study provide a link between HCMV reactivation and immune homeostasis, and thus help to establish a prophylaxis and diagnosis of HCMV reactivation following HSCT. Assessment of clonal diversity of TCR against HCMV may provide important insights into the molecular basis of $\mathrm{T}$ cell immunodominance. However, further investigation is necessary to address this issue in recipients of HSCT. 
Table IV. HCMV antigenemia status and TCR BV9/BV11 expression among the 3 recipients of allogeneic hematopoietic stem cell transplantation.

HCMV antigenemia

\section{Recipient TCR BV9 TCR BV11 HCMV-pp65 HCMV-IE}

\begin{tabular}{lllll}
\hline 1 & - & - & - & - \\
2 & + & + & + & + \\
3 & + & + & + & + \\
\hline
\end{tabular}

TCR BV9/11+, recipients who preferentially expressed TCR BV9/11; TCR BV9/11', recipients who did not express TCR BV9/11; HCMV-pp65/IE ${ }^{+}$, recipients who exhibited pp65/IE antigenemia; HCMV-pp65/IE, recipients who were free of pp65/IE antigenemia. TCR BV, T-cell receptor $\beta$ variable; HCMV, human cytomegalovirus; IE, immediate early.

\section{Acknowledgements}

The present study was supported by the National Natural Science Foundation of China (grant no. 30872239) and the Zhejiang Provincial Natural Science Foundation of China (grant no. LY14H190002).

\section{References}

1. Gratama JW and Cornelissen JJ: Diagnostic potential of tetramer-based monitoring of cytomegalovirus-specific $\mathrm{CD}^{+}$ $\mathrm{T}$ lymphocytes in allogeneic stem cell transplantation. Clin Immunol 106: 29-35, 2003.

2. Mori T and Kato J: Cytomegalovirus infection/disease after hematopoietic stem cell transplantation. Int J Hematol 91: 588-595, 2010

3. Moins-Teisserenc H, Busson M, Scieux C, Bajzik V, Cayuela JM, Clave E, de Latour RP, Agbalika F, Ribaud P, Robin M, et al Patterns of cytomegalovirus reactivation are associated with distinct evolutive profiles of immune reconstitution after allogeneic hematopoietic stem cell transplantation. J Infect Dis 198: 818-826, 2008

4. Gamadia LE, Rentenaar RJ, Baars PA, Remmerswaal EB, Surachno S, Weel JF, Toebes M, Schumacher TN, ten Berge IJ and van Lier RA: Differentiation of cytomegalovirus-specific CD8(+) T cells in healthy and immunosuppressed virus carriers. Blood 98: 754-761, 2001.

5. Alli R, Zhang ZM, Nguyen P, Zheng JJ and Geiger TL: Rational design of $\mathrm{T}$ cell receptors with enhanced sensitivity for antigen. PLoS One 6: e18027, 2011.

6. Bohne F, Chmielewski M, Ebert G, Wiegmann K, Kürschner T, Schulze A, Urban S, Krönke M, Abken H and Protzer U: T cell redirected against hepatitis $\mathrm{B}$ virus surface proteins eliminate infected hepatocytes. Gastroenterology 134: 239-247, 2008.

7. Sommermeyer D, Neudorfer J, Weinhold M, Leisegang M, Engels B, Noessner E, Heemskerk MH, Charo J, Schendel DJ, Blankenstein T, et al: Designer T cells by $\mathrm{T}$ cell receptor replacement. Eur J Immunl 36: 3052-3059, 2006.

8. Torelli GF, Lucarelli B, Iori AP, De Propris MS, Capobianchi A, Barberi W, Valle V, Iannella E, Natalino F, Mercanti C, et al: The immune reconstitution after an allogeneic stem cell transplant correlates with the risk of graft-versus-host disease and cytomegalovirus infection. Leuk Res 35: 1124-1126, 2011.

9. Abu-Khader A and Krause S: Rapid monitoring of immune reconstitution after allogeneic stem cell transplantation-a comparison of different assays for the detection of cytomegalovirus-specific T cells. Eur J Haematol 91: 534-545, 2013.
10. Yang JZ, Li MW, Wang JG, Lu HF, Yao XS, He JQ and Li LJ: Rapid detection of clonal expansion of T-cell receptor-beta gene in patients with HBV using the real-time PCR with DNA melting curve analysis. Hepatol Res 40: 407-414, 2010.

11. Yang J, He J, Lu H, Wei L, Li S, Wang B, Diao H and Li L: Molecular features of the complementarity determining region 3 motif of the T cell population and subsets in the blood of patients with chronic severe hepatitis B. J Transl Med 9: 210, 2011.

12. Arenz M, Meyer zum Büschenfelde KH and Löhr HF: Limited T cell receptor Vbeta-chain repertoire of liver-infiltrating T cells in autoimmune hepatitis. J Hepatol 28: 70-77, 1988.

13. Yang J, He J, Huang H, Ji Z, Wei L, Ye P, Xu K and Li L: Molecular characterization of $\mathrm{T}$ cell receptor beta variable in the peripheral blood $\mathrm{T}$ cell repertoire in subjects with active tuberculosis or latent tuberculosis infection. BMC Infect Dis 13: 423, 2013.

14. Fan J, Zhang X, Chen XM, Gao HN, Yang MF, Zhao H, Hu JH and Ma WH: Monitoring of human cytomegalovirus glycoprotein B genotypes using real-time quantitative PCR in immunocompromised Chinese patients. J Virol Methods 160: 74-77, 2009.

15. Zhang X, Huang YP, Gao HN, Yang MF, Zhao H, Hu JH, Chen XM, Ma WH and Fan J: Quantification of cytomegalovirus glycoprotein Bn DNA in hematopoietic stem cell transplant recipients by real-time PCR. PLoS One 7: e51224, 2012.

16. Liu A, Ma Y, Wu W, Chen X, Huang Y, Hu J, Liang H, Wang H, Yang R and Fan J: Evaluation of human cytomegalovirus-specific $\mathrm{CD} 8^{+} \mathrm{T}$-cells in allogeneic haematopoietic stem cell transplant recipients using pentamer and interferon- $\gamma$-enzyme-linked immunospot assays. J Clin Virol 58: 427-431, 2013.

17. Fields BA, Ober B, Malchiodi EL, Lebedeva MI, Braden BC, Ysern X, Kim JK, Shao X, Ward ES and Mariuzza RA: Crystal structure of the $\mathrm{V}$ alpha domain of a $\mathrm{T}$ cell antigen receptor. Science 270: 1821-1824, 1995.

18. van de Berg PJ, van Stijn A, Ten Berge IJ and van Lier RA: A fingerprint left by cytomegalovirus infection in the human $\mathrm{T}$ cell compartment. J Clin Virol 41: 213-217, 2008.

19. Nakasone H, Tanaka Y, Yamazaki R, Terasako K, Sato M, Sakamoto K, Yamasaki R, Wada H, Ishihara Y, Kawamura K, et al: Single-cell T-cell receptor- $\beta$ analysis of HLA-A*2402-restricted CMV-pp65-specific cytotoxic T-cells in allogeneic hematopoietic SCT. Bone Marrow Transplant 49: 87-94, 2104.

20. Engstrand M, Lidehall AK, Totterman TH, Herrman B, Eriksson BM and Korsgren O: Cellular responses to cytomegalovirus in immunosuppressed patients: Circulating $\mathrm{CD}^{+} \mathrm{T}$ cells recognizing CMVpp65 are present but display functional impairment. Clin Exp Immunol 132: 96-104, 2003.

21. Ozdemir E, St John LS, Gillespie G, Rowland-Jones S, Champlin RE, Molldrem JJ and Komanduri KV: Cytomegalovirus reactivation following allogeneic stem cell transplantation is associated with the presence of dysfunctional antigen-specific CD8 ${ }^{+}$T cells. Blood 100: 3690-3697, 2002.

22. Matsumoto Y, Matsuo H, Sakuma H, Park IK, Tsukada Y, Kohyama K, Kondo T, Kotorii S and Shibuya N: CDR3 spectratyping analysis of the TCR repertoire in myasthenia gravis. J Immunol 176: 5100-5107, 2006

23. Frankel TL, Burns WR, Peng PD, Yu Z, Chinnasamy D, Wargo JA, Zheng Z, Restifo NP, Rosenberg SA and Morgan RA: Both CD4 and CD8 T cells mediate equally effective in vivo tumor treatment when engineered with a highly avid TCR targeting tyrosinase. J Immunol 184: 5988-5998, 2010.

24. Ray S, Chhabra A, Chakraborty NG, Hegde U, Dorsky DI, Chodon T, von Euw E, Comin-Anduix B, Koya RC, Ribas A, et al: MHC-Irestricted melanoma antigen specific TCR-engineered human $\mathrm{CD}^{+} \mathrm{T}$ cells exhibit multifunctional effector and helper responses, in vitro. Clin Immunol 136: 338-347, 2010.

25. Kerkar SP, Sanchez-Perez L, Yang S, Borman ZA, Muranski P, Ji Y, Chinnasamy D, Kaiser AD, Hinrichs CS, Klebanoff CA, et al: Genetic engineering of murine $\mathrm{CD}^{+}$and $\mathrm{CD} 4^{+} \mathrm{T}$ cells for preclinical adoptive immunotherapy studies. J Immunother 34: 343-352, 2011.

26. Wang QJ, Hanada K, Feldman SA, Zhao Y, Inozume T and Yang JC: Development of a genetically-modified novel T-cell receptor for adoptive cell transfer against renal cell carcinoma. J Immunol Methods 366: 43-51, 2011.

27. Fan J, Meng XQ, Yang MF, Zhou L, Chen XM, Hu MJ, Fan WW, Ma WH and Li LJ: Association of cytomegalovirus infection with human leukocyte antigen genotypes in recipients after allogeneic liver transplantation. Hepatobiliary Pancreat Dis In 5: 34-38, 2006. 